\title{
Risk factors associated with mortality in newborn infants with congenital diaphragmatic hernia
}

\author{
María F. Galletti, M.D., ${ }^{a}$ Carolina Giudice, M.D., ${ }^{a}$ Pablo H. Brener Dik, M.D., ${ }^{a}$ \\ Silvia Fernández Jonusas, M.D., ${ }^{a}$ Luisa Baldini, M.D., ${ }^{a}$ and Gonzalo L. Mariani, M.D. ${ }^{a}$
}

\begin{abstract}
Introduction. Morbidity and mortality are high in congenital diaphragmatic hernia. Some tools help to predict survival, both prenatally (observed/expected lung-to-head ratio [OELHR], presence of the liver in the chest) and postnatally (Congenital Diaphragmatic Hernia Study Group [CDHSG] score). Our objective was to identify the risk factors associated with mortality and estimate the risk-adjusted mortality in the prenatal period in the subgroup of patients with isolated left-sided hernia.

Population and methods. Retrospective and analytical study of patients born at Hospital Italiano de Buenos Aires between 2011 and 2018. A multivariate analysis was done to assess mortality-associated risk factors. For riskadjusted mortality in the prenatal period, the ratio between the observed mortality and the mean "expected" mortality based on the OELHR was estimated.

Results. A total of 53 patients were included. Their median gestational age was 38 weeks, and their mean birth weight was $3054 \mathrm{~g}$. Isolated hernia was observed in $73 \%$ of patients. Overall mortality was $45 \%$, and higher in patients with associated malformations. In the multivariate analysis, the presence of severe pulmonary hypertension estimated by postnatal echocardiogram was independently associated with mortality (adjusted odds ratio: 6.4, $95 \%$ confidence interval: 1.02-40). The observed overall mortality in patients with isolated left-sided hernia was similar to that expected (ratio: 1.05).

Conclusion. Overall mortality was similar to that expected based on the OE-LHR. In our population, severe pulmonary hypertension after birth was a determining factor of mortality. Key words: congenital diaphragmatic hernia, neonatal mortality, risk factors, pulmonary hypertension.
\end{abstract}

http: / / dx.doi.org/10.5546/ aap.2020.eng.180

E-mail address:

María F. Galletti, M.D.: maria.galletti@

hospitalitaliano.org.ar

Funding:

None.

Conflict of interest:

None.

Received: 4-4-2019

Accepted: 12-3-2019

\section{INTRODUCTION}

Congenital diaphragmatic hernia $(\mathrm{CDH})$ is an anomaly present in 1 out of every 2500-4000 newborn infants (NBIs). ${ }^{1}$ Overall mortality from this condition is $40-60 \%$; and respiratory morbidity, $15-25 \%$. In 85$90 \%$ of cases, $\mathrm{CDH}$ is left-sided, and $30-40 \%$ of patients have chromosome diseases or genetic disorders and associated anomalies that lead to a higher mortality., ${ }^{2,3}$

Pulmonary hypoplasia is a determining factor of morbidity and mortality. Therefore, the prediction based on prenatal risk factors has focused on ultrasound and magnetic resonance imaging of the lungs. ${ }^{4-7}$ The observed / expected lung-tohead ratio (OE-LHR) is the tool most commonly used to estimate prenatal risk. It has been validated exclusively in patients with isolated left-sided $\mathrm{CDH}$ and is a marker of pulmonary hypoplasia. ${ }^{8}$

The OE-LHR is combined with the presence of liver in the chest to estimate the degree of pulmonary hypoplasia and predict postnatal survival. Thus, patients with an OELHR $<15 \%$ have extreme pulmonary hypoplasia with no reports of survivors; those with an OE-LHR of $15-25 \%$ have severe pulmonary hypoplasia with a survival of $20 \%$; and those with an OE-LHR of 26-35\% and $36-45 \%$ and liver in the chest have moderate pulmonary hypoplasia with a survival of 30-60\%. Finally, fetuses with an OE-LHR $>45 \%$ and $36-45 \%$ with the liver in the abdomen have mild pulmonary hypoplasia and a survival of more than $75 \%$. ${ }^{9}$

There is a tool available to stratify patients into categories with different risks for death in the immediate 
postnatal period that has been validated by the Congenital Diaphragmatic Hernia Study Group (CDHSG). ${ }^{10}$ The model includes the following outcome measures: Apgar score at 5 minutes $<7$, congenital heart disease and / or chromosomal abnormalities, severe pulmonary hypertension (PHT) diagnosed by echocardiogram, and small for gestational age (SGA). This way, three groups with different probabilities of death are identified: score 0 , low risk $(<10 \%)$; score 1-2, intermediate risk (25\%); and score $\geq 3$, high risk for mortality $(50 \%)$.

PHT occurs in the postnatal period as a manifestation of pulmonary vascular alterations. However, it is difficult to predict PHT in the prenatal period with the tools currently available. ${ }^{5}$ A color Doppler echocardiogram is required in the postnatal period to estimate PHT. ${ }^{11}$ It is directly related to the degree of hypoxemia, an indicator of mortality in the short term. ${ }^{12}$

In our setting, few studies on $\mathrm{CDH}$ have been published, ${ }^{13}$ so it is necessary to consult the international bibliography. It may be useful to disseminate our experience working at a facility that offers a program to care for high-risk pregnancies and a level IIIB neonatal intensive care unit, where an important number of cases may be recorded to conduct this study. Our primary objective was to identify risk factors associated with mortality in the neonatal period in a group of patients diagnosed with $\mathrm{CDH}$. Our secondary objective was to estimate the riskadjusted mortality in the prenatal period in the subgroup of patients with isolated left-sided congenital diaphragmatic hernia (LCDH).

\section{MATERIAL AND METHODS}

Design: Observational and analytical study conducted in a retrospective cohort.

Population: All NBIs with CDH who received antenatal care follow-up and were born at Hospital Italiano de Buenos Aires (HIBA) were included successively between 2011 and 2018 .

Exclusion criteria: NBIs with treatment adjustment from birth were included only to estimate overall mortality. For the risk-adjusted mortality in the prenatal period, NBIs with rightsided $\mathrm{CDH}$, associated major malformations and/or chromosomal abnormalities, and patients without registration of OE-LHR were excluded.

Data collection: A database was created to include the outcome measures collected from a prospective, secondary source. If any piece of data was missing, it was obtained from the electronic medical record (EMR). The following outcome measures were collected: birth weight (BW), gestational age (GA), sex, delivery mode, type of mechanical ventilation (conventional MV and/or high frequency oscillatory ventilation [HFOV]) at baseline (in the first 12 hours of life) and during hospitalization, surfactant requirement, inhaled nitric oxide (iNO), initiation of extracorporeal membrane oxygenation (ECMO), oxygenation index (OI) at baseline (first value available in the first 12 hours of life), complications during hospitalization (confirmed or clinical sepsis, pneumothorax, and chylothorax), components of prenatal (OE-LHR defined as the observed percentage of the lung volume contralateral to the lesion over that expected for each GA, presence of liver in the chest) and postnatal prediction tools. Severe PHT was defined by an echocardiogram performed in the first 24 hours of life based on foramen ovale and ductal flow.

Statistical analysis: Measures of central tendency and dispersion, based on sample distribution, were estimated for continuous outcome measures. Measures of frequency were estimated for categorical outcome measures; they were reported as percentages. A univariate analysis was performed to establish an association between studied outcome measures and mortality. The $t$ test or a non-parametric test were done for continuous outcome measures, based on their distribution. The $\chi^{2}$ test or Fisher's exact test were used for categorical outcome measures, as applicable.

A multivariate analysis was done to establish whether the components of pre- and postnatal prediction tools behaved as independent outcome measures associated with mortality. The OE-LHR and severe PHT outcome measures were included because both showed a significant association in the univariate analysis. This was only done in patients with isolated LCDH because the OELHR has been validated only in this population. The crude and adjusted odds ratio (OR) with the corresponding $95 \%$ confidence interval (CI) and the $p$ value were reported.

A receiver operating characteristic (ROC) curve was done; the area under the curve (AUC) was reported, and the Hosmer-Lemeshow test was done to assess the model's goodness of fit. To estimate the risk-adjusted mortality in the prenatal period, the ratio between the mortality observed in our population and the mean "expected" mortality based on each patient's OE-LHR was obtained. A value of $p<0.05$ was considered significant. 
Ethical considerations: The study was approved by the Ethics Committee for Research Protocols of our hospital.

\section{RESULTS}

During the study period, 16285 NBIs were born; of them, 55 had $\mathrm{CDH}$. The incidence was $3.4 \%$, which was equivalent to a mean of 7 cases per year, and overall mortality (including the 2 patients whose treatment was adjusted at birth) was $45 \%$. Figure 1 shows the flow chart of patients.

The baseline characteristics of included patients are described in Table 1. Among patients with isolated LCDH, survival was $59 \%$, whereas among those with malformations and/or genetic disorders, $36 \%$. Among the patients who only had congenital heart disease as an associated malformation $(n=6), 2$ survived.

In relation to respiratory support, 45 patients required $\mathrm{HFOV}, 36$ received iNO and 3 required ECMO. The indication for ECMO was done before surgery in 2 of these patients. The third patient required ECMO after a surgery in the setting of air leak and PHT exacerbation and survived after hospital discharge. Pulmonary surfactant was administered to 16 patients. Surgery was performed in 35 patients; 14 developed chylothorax as a postoperative complication, and
5 patients died in the postoperative period.

Table 2 shows the univariate analysis. Compared to the group of survivors, that of dead patients had a younger GA and a lower BW, both statistically significant. The administration of iNO, surfactant, baseline OI, and HFOV requirement in the first 12 hours of life were higher among dead patients. Table 3 shows the components of pre- and postnatal prediction tools compared by mortality. In the group of dead patients, the frequency of presence of liver in the chest and severe PHT was higher. In addition, these patients tended to have a lower Apgar score at 5 minutes, together with an associated malformation and/or genetic disorder. The OELHR and the postnatal score were statistically

TABLE 1. Baseline characteristics of the population $(n=53)$

\begin{tabular}{lc}
\hline GA in weeks; median (IQR) & $38(38-39)$ \\
BW in grams; mean (SD) & $3054(510)$ \\
Female sex, n (\%) & $29(55)$ \\
Vaginal delivery, n (\%) & $15(28)$ \\
Type of diaphragmatic hernia & \\
Isolated left-sided, n (\%) & $39(73)$ \\
Associated malformations, $\mathrm{n}(\%)$ & $12(22)$ \\
\hline
\end{tabular}

GA: gestational age; BW: birth weight;

IQR: 25-75 interquartile range; SD: standard deviation.

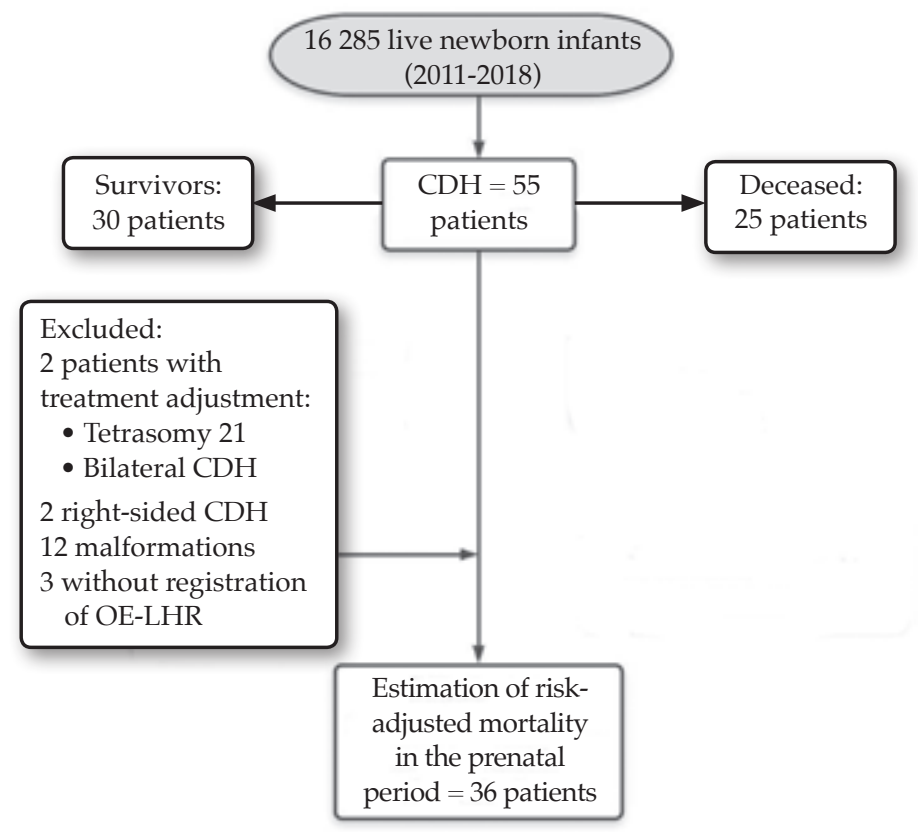

CDH: congenital diaphragmatic hernia; OE-LHR: observed/expected lung-to-head ratio. 
different between them.

The multivariate analysis model included the OE-LHR and severe PHT, as pre- and postnatal predictive outcome measures. Table 4 shows the crude and adjusted OR and the area under the ROC curve. Postnatal diagnosis of severe PHT demonstrated to be an independent risk factor for mortality adjusted by the OE-LHR. The HosmerLemeshow test of this model was significant $(p=0.53)$.

Lastly, the observed mortality over expected mortality based on the prenatal prediction tool $(n=36)$ was estimated. The expected overall mortality was $31.5 \%$, whereas the observed overall mortality was $33.3 \%$, with a ratio of 1.05 .

\section{DISCUSSION}

Based on the results observed at our unit, 1 in every 300 newborn infants has $\mathrm{CDH}$. This reflects a higher incidence than that reported in epidemiological studies ${ }^{1,2,14,15}$ because this is a fetal referral center. According to the bibliography, it has been demonstrated that survival is higher at facilities with a high volume of patients with $\mathrm{CDH}$, which may partially explain the variation in mortality in these patients. ${ }^{16,17}$

Table 2. Univariate analysis. Demographic and postnatal course outcome measures based on mortality

\begin{tabular}{|c|c|c|c|}
\hline Outcome measures & Survivors, $\mathrm{n}=30$ & Non-survivors, $\mathrm{n}=23$ & $p$ value \\
\hline GA in weeks; median (IQR) & $39(38-39)$ & $38(38-38)$ & $0.017^{* * *}$ \\
\hline $\mathrm{BW}$ in grams; mean (SD) & $3204( \pm 382)$ & $2848( \pm 593)$ & $0.013^{\star *}$ \\
\hline Female sex, n $(\%)$ & $13(43.3)$ & $16(69.5)$ & $0.057^{*}$ \\
\hline Vaginal delivery, n (\%) & $10(33.3)$ & $5(21.7)$ & $0.54 \dagger$ \\
\hline Isolated LCDH, $\mathrm{n}(\%)$ & $25(83)$ & $14(60.9)$ & $0.11+$ \\
\hline Congenital heart disease, $\mathrm{n}(\%)$ & $2(6.7)$ & $4(17.4)$ & $0.38+$ \\
\hline HFOV, n $(\%)$ & $22(73.3)$ & $23(100)$ & $0.007+$ \\
\hline Surfactant, n $(\%)$ & $3(10)$ & $13(56.5)$ & $0.001+$ \\
\hline iNO, n (\%) & $14(46.6)$ & $22(95.6)$ & $0.001+$ \\
\hline Baseline AMV, n (\%) & $19(63.3)$ & $2(8.7)$ & $0.001+$ \\
\hline Baseline HFOV, n (\%) & $11(36.6)$ & $21(91.3)$ & $0.001 \dagger$ \\
\hline Baseline OI; median (IQR) & $6.7(4-10.5)$ & $25.2(15.7-31)$ & $0.001^{* * *}$ \\
\hline Sepsis, n (\%) & $15(50)$ & $8(34.8)$ & 0.27 \\
\hline Chylothorax, $\mathrm{n}(\%) ; \mathrm{n}=35$ & $10(33.3)$ & $4(80)$ & $0.13+$ \\
\hline Pneumothorax, n $(\%)$ & $7(23.3)$ & $5(21.7)$ & $0.89+$ \\
\hline
\end{tabular}

GA: gestational age; BW: birth weight; LCDH: left-sided congenital diaphragmatic hernia;

HFOV: high frequency oscillatory ventilation; iNO: inhaled nitric oxide; AMV: assisted mechanical ventilation;

OI: oxygenation index; IQR: 25-75 interquartile range; SD: standard deviation. $\left({ }^{*}\right) \chi^{2}$. (†) Fisher. $\left({ }^{* *}\right)$ T test. $\left({ }^{* * *}\right)$ Mann-Whitney.

TABLE 3. Univariate analysis. Components of prenatal and postnatal prediction tools

\begin{tabular}{|c|c|c|c|}
\hline Outcome measures & Survivors, $(\mathrm{n}=30)$ & Non-survivors, $(\mathrm{n}=23)$ & $p$ value \\
\hline OE-LHR \% (median and IQR); $\mathrm{n}=36$ & $48(35-66)$ & $36.5(31-41)$ & $0.04^{* * *}$ \\
\hline Liver in the chest, $\mathrm{n}(\%)$ & $12(40)$ & $17(73.9)$ & $0.014^{*}$ \\
\hline $\mathrm{SGA}, \mathrm{n}(\%)$ & $2(6.7)$ & $5(21.7)$ & $0.21+$ \\
\hline Apgar at 5 minutes $<7, \mathrm{n}(\%)$ & $2(6.9)$ & $7(30.4)$ & $0.06+$ \\
\hline Severe PHT, n $(\%)$ & $11(36.6)$ & $19(86.3)$ & $0.001+$ \\
\hline Associated malformation, $\mathrm{n}(\%)$ & $5(16.7)$ & $9 \mathrm{a} \approx(39.1)$ & $0.11+$ \\
\hline Postnatal score, median (IQR) & $1.5(0-2)$ & $2(2-3)$ & $0.001^{* * *}$ \\
\hline
\end{tabular}

OE-LHR: observed/ expected lung-to-head ratio; SGA: small for gestational age; PHT: pulmonary hypertension; IQR: 25-75 interquartile range. $\left(^{*}\right) \chi^{2} .(\dagger)$ Fisher. $\left({ }^{* *}\right)$ T test. $\left({ }^{* * *}\right)$ Mann-Whitney.

TABLE 4. Multivariate analysis assessing mortality-associated factors in patients with isolated left-sided congenital diaphragmatic hernia $(n=36)$

\begin{tabular}{lcccc}
\hline & \multicolumn{2}{c}{ Univariate analysis } & \multicolumn{2}{c}{ Multivariate analysis } \\
\cline { 2 - 5 } Outcome measure & OR $(\mathbf{9 5} \% \mathbf{C I})$ & $p$ value & aOR $(\mathbf{9 5} \% \mathbf{C I})^{*}$ & $p$ value \\
\hline OE-LHR & $0.94(0.88-0.99)$ & 0.04 & $0.96(0.89-1.02)$ & 0.28 \\
Severe PHT & $12(2.2-70)$ & 0.004 & $6.4(1.02-40)$ & $\mathbf{0 . 0 4 7}$ \\
\hline
\end{tabular}

OE-LHR: observed / expected lung-to-head ratio; PHT: pulmonary hypertension; aOR: adjusted odds ratio; CI: confidence interval. Area under the ROC curve: 0.81 . Pseudo-R2 $=0.21$. 
In recent decades, different strategies have been implemented and demonstrated an increased survival, such as initial stabilization, delayed surgery, and HFOV, iNO, and ECMO use, among others. ${ }^{2-18-20}$ However, it is worth noting that survival rates may have been overestimated due to a selection bias by ignoring hidden mortality (fetal and immediate neonatal deaths before transfer). ${ }^{3}$ For example, Javid et al. (Canadian Neonatal Network) reported an overall survival of $82 \%$, leaving out more severe patients who died before or during transfer and those who were directly admitted to the pediatric intensive care unit for ECMO.$^{17}$ In our cohort, the overall survival was in the range of variability reported by epidemiological studies: Colvin et al. (Australia), ${ }^{2} 52 \%$; Harting et al. (CDHSG) ${ }^{21} 68 \%$. Our results correspond exclusively to patients born at our hospital, so they would account for a survival rate free of case selection.

Different mortality-associated risk factors were identified. Dead patients had a younger GA and a lower BW compared to survivors, which is similar to what has been reported by different authors. ${ }^{2,21,22}$ However, other studies, including a systematic review, did not find such difference. ${ }^{23,24}$ In our cohort, GA was in the range of early term. The available bibliography appears to be insufficient to establish an optimal time for birth. Stevens et al..$^{25}$ have concluded that birth at 37-38 weeks is associated with a higher survival compared to 39-41 weeks, whereas Hutcheon et al. have demonstrated the opposite. ${ }^{26}$ The European consensus recommends planning a delivery after a GA of 39 weeks in a high-volume tertiary center. ${ }^{27}$

Patients with $\mathrm{CDH}$ and associated malformations have a worse prognosis. ${ }^{1-2,14}$ The CDHSG reported an overall incidence of heart defects in patients with $\mathrm{CDH}$ of $17.8 \% .{ }^{28}$ The most frequent heart defects included hypoplastic left heart syndrome and coarctation of the aorta, with a survival of $14 \%$ and $46 \%$, respectively. The incidence was higher among patients with right obstructive lesions. ${ }^{28}$ Similarly to what has been reported, in our study, mortality in patients with associated malformations and/or disorders was almost twice as high compared to those with isolated LCDH.

In relation to health care services, in our study, dead patients more frequently received HFOV, iNO, and pulmonary surfactant. This may be due to the increased severity and the use of rescue therapies. Likewise, the group of dead patients more commonly required baseline HFOV, whereas survivors received significantly more conventional MV. A multicenter study randomized 171 patients with $\mathrm{CDH}$ born at 34 weeks of gestation or more to receive either conventional MV or HFOV. Although that study did not establish differences in the primary outcome measure of death/bronchopulmonary dysplasia, the group randomized to HFOV needed MV for a longer time and required more vasoactive drugs, sildenafil, iNO, and ECMO. ${ }^{29}$

A study that included a multivariate analysis found an independent association between the administration of pulmonary surfactant and mortality. Beyond the observational design, that study concluded that surfactants did not provide any benefit. ${ }^{30} \mathrm{~A}$ meta-analysis on the use of iNO in NBIs with PHT showed that, in the subgroup of patients with $\mathrm{CDH}$, iNO did not reduce the death/ECMO use outcome. ${ }^{31}$ However, the CDH EURO Consortium Consensus recommends considering its use if there is evidence of a rightto-left shunt through the foramen ovale and/ or ductus, OI above 20 and / or a difference in pre-/ post-ductal saturation above $10 \%$, with echocardiographic evidence of an adequate left ventricular function. ${ }^{27}$

Neonatal diseases with a higher ECMO requirement include meconium aspiration syndrome (MAS), $\mathrm{CDH}, \mathrm{PHT}$, sepsis, neonatal respiratory distress syndrome, among others. With the advent of therapeutic alternatives, such as surfactant, HFOV, and iNO use, the indication for ECMO has decreased drastically in this population..$^{32}$ Among patients with $\mathrm{CDH}, \mathrm{ECMO}$ indication has become a rescue strategy in the case of severe respiratory failure, with a reduction of early mortality.

A meta-analysis of retrospective studies showed a higher rate of short- and long-term survival in units where ECMO was available; ${ }^{33}$ according to the Extracorporeal Life Support Organization (ELSO) reports, survival was up to $74 \%$ at the time of hospital discharge. ${ }^{34} \mathrm{ECMO}$ use in $\mathrm{CDH}$ has progressively decreased and been reserved for preoperative stabilization of patients who meet specific criteria. At our site, where the neonatal respiratory ECMO program has been recently implemented, patients have been strictly individualized to receive this therapy.

In relation to the components of prenatal mortality prediction, the group of dead patients had a significantly higher percentage of liver herniation and a statistically lower OE-LHR score 
compared to the group of survivors, which is similar to what has been observed in the studies where they were developed. ${ }^{4,8,9}$ In this study, mortality was similar to that expected in patients with isolated LCDH; therefore, in this cohort of patients, the OE-LHR was, in theory, an accurate prediction tool.

The postnatal score and severe PHT, in addition to the OI, were significantly different between both groups. In the multivariate analysis, postnatal PHT diagnosis was associated with mortality, regardless of the OE-LHR, an outcome measure that lost statistical significance. It is worth noting such finding because it implies that, although this prenatal diagnostic tool is very useful, it would be wise to wait until birth to make a better prognosis. Since it is difficult to know PHT and ventricular dysfunction behavior in advance, it is necessary to perform an echocardiogram to assess ventricular discordance and structural changes in the left ventricle that may predict cardiopulmonary deterioration at birth. ${ }^{11}$ Prenatal methods have been proposed to estimate PHT, including lung volume and color Doppler ultrasound to observe the different pressures in the lung circuit, although they are still being studied. ${ }^{27}$

This study has certain limitations. On the one side, given its design, it is not possible to establish the causality between studied risk factors and mortality. In addition, due to the number of patients, we cannot rule out the presence of a type II error. On the other side, this is the first study in our setting to assess the factors that may hinder patients' course.

It is critical to perform both prenatal and postnatal assessments in order to identify factors and provide guidance to the families on the need to have the baby born at a tertiary care facility for a multidisciplinary approach. It may be concluded that, although there are several factors associated with mortality, in this cohort of patients, severe PHT immediately after birth was a determining factor.

\section{REFERENCES}

1. Tovar JA. Congenital Diaphragmatic Hernia. Orphanet $J$ Rare Dis. 2012; 7(1):1.

2. Colvin J, Bower C, Dickinson JE, Sokol J. Outcomes of Congenital Diaphragmatic Hernia: A Population-Based Study in Western Australia. Pediatrics. 2005;116(3):e356-63.

3. Stege G, Fenton A, Jaffray B. Nihilism in the 1990s: the true mortality of diaphragmatic hernia. Pediatrics. 2003; 112(3 Pt 1):532-5.

4. Jani J, Keller RL, Benachi A, Nicolaides KH, et al. Prenatal prediction of survival in isolated left-sided diaphragmatic hernia. Ultrasound Obstet Gynecol. 2006; 27(1):18-22.

5. Benachi A, Cordier A, Cannie M, JaniJ. Advances in prenatal diagnosis of congenital diaphragmatic hernia. Semin Fetal Neonatal Med. 2014; 19(6):331-7.

6. Nawapun K, Eastwood M, Sandaite I, Dekoninck P, et al. Correlation of observed-to-expected total fetal lung volume with intrathoracic organ herniation on magnetic resonance imaging in fetuses with isolated left-sided congenital diaphragmatic hernia. Ultrasound Obstet Gynecol. 2015; 46(2):162-7.

7. Zamora IJ, Olutoye OO, Cass DL, Fallon SC, et al. Prenatal MRI fetal lung volumes and percent liver herniation predict pulmonary morbidity in congenital diaphragmatic hernia (CDH). J Pediatr Surg. 2014; 49(5):688-93.

8. Jani J, Nicolaides KH, Keller RL, Benachi A, et al. Observed to expected lung area to head circumference ratio in the prediction of survival in fetuses with isolated diaphragmatic hernia. Ultrasound Obstetr Gynecol. 2007; 30(1):67-71.

9. Deprest JA, Flemmer AW, Gratacos E, Nicolaides K. Antenatal prediction of lung volume and in-utero treatment by fetal endoscopic tracheal occlusion in severe isolated congenital diaphragmatichernia. Semin Fetal Neonatal Med. 2009; 14(1):8-13.

10. Brindle ME, Cook EF, Tibboel D, Lally PA, et al. A clinical prediction rule for the severity of congenital diaphragmatic hernias in newborns. Pediatrics. 2014; 134(2):e413-9.

11. Kinsella JP, Steinhorn RH, Mullen MP, Hopper RK, et al. The left ventricle in congenital diaphragmatic hernia: implications for the management of pulmonary hypertension. J Pediatr. 2018; 197:17-22.

12. Mann P, Morriss F Jr, Klein J. Prediction of survival in infants with congenital diaphragmatic hernia based on stomach position, surgical timing, and oxygenation index. Am J Perinatol. 2012; 29(5):383-90.

13. Salas G, Reusmann A, Boglione M, Rubio M, et al. Hernia diafragmática congénita bilateral de diagnóstico tardío: reporte de un caso. Arch Argent Pediatr. 2016; 114(1):e29-31.

14. Yang W, CarmichaelSL, HarrisJA, Shaw GM. Epidemiologic Characteristics of CongenitalDiaphragmatic Hernia among 2.5 Million California Births, 1989-1997. Birth Defects Res A Clin Mol Teratol. 2006; 76(3):170-4.

15. Gallot D, Boda C, Ughetto S, Perthus I, et al. Prenatal detection and outcome of congenital diaphragmatic hernia: a French registry-based study. Ultrasound Obstet Gynecol. 2007; 29(3):276-83.

16. Grushka JR, Laberge J-M, Puligandla P, Skarsgard ED. Effect of hospital case volume on outcome in congenital diaphragmatic hernia: the experience of the Canadian Pediatric Surgery Network. J Pediatr Surg. 2009; 44(5):873-6.

17. Javid PJ, Jaksic T, Skarsgard ED, Lee S. Survival rate in Congenital Diaphragmatic Hernia: The Experience of The Canadian Neonatal Network. J Pediatr Surg. 2004; 39(5):657-60.

18. Cacciari A, Ruggeri G, Mordenti M, Ceccarelli PL, et al. High-frequency oscillatory ventilation versus conventional mechanical ventilation in congenital diaphragmatichernia. Eur J Pediatr Surg. 2001; 11(1):3-7.

19. Okuyama H, Kubota A, Oue T, Kuroda S, et al. Inhaled nitric oxide with early surgery improves the outcome of antenatally diagnosed congenital diaphragmatic hernia. J Pediatr Surg. 2002; 37(8):1188-90.

20. Frenckner B, Ehrén H, Granholm T, Lindén V, et al. Improved results in patients who have congenital diaphragmatic hernia using preoperative stabilization, extracorporeal membrane oxygenation, and delayed surgery. J Pediatr Surg. 1997; 32(8):1185-9.

21. Harting MT, Lally KP. The Congenital Diaphragmatic Hernia Study Group registry update. Semin Fetal Neonatal 
Med. 2014; 19(6):370-5.

22. Oh C, Youn JK, Han JW, Yang HB, et al. Predicting survival of congenital diaphragmatic hernia on the first day of life. World J Surg. 2018; 43(1):282-90.

23. Aihole J, Gowdra A, Javaregowda D, Jadhav V, et al. A clinical study on congenital diaphragmatic hernia in neonates: Our institutional experience. J Indian Assoc Pediatr Surg. 2018; 23(3):131-9.

24. Vieira R, Pearse R, Rankin J. Mortality factors in infants with congenital diaphragmatichernia: A systematic review. Birth Defects Res. 2018; 110(16):1241-9.

25. Stevens TP, Van Wijngaarden EV, Ackerman KG, Lally PA, et al. Timing of delivery and survival rates for infants with prenatal diagnoses of congenital diaphragmatic hernia. Pediatrics. 2009; 123(2):494-502.

26. Hutcheon J, Butler B, LisonkovaS, Marquette G, et al. Timing of delivery for pregnancies with congenital diaphragmatic hernia. BJOG. 2010; 117(13):1658-62.

27. Snoek KG, Reiss IK, Greenough A, Capolupo I, et al. Standardized Postnatal Management of Infants with Congenital Diaphragmatic Hernia in Europe: The CDH EURO Consortium Consensus - 2015 Update. Neonatology. 2016; 110(1):66-74.

28. Menon SC, Tani LY, Weng HY, Lally PA, et al. Clinical characteristics and outcomes of patients with cardiac defects and congenital diaphragmatic hernia. J Pediatr. 2013; 162(1):114-9.e2.

29. Snoek KG, Capolupo I, Van Rosmalen JV, Hout Lde $\mathrm{J}$, et al. Conventional Mechanical Ventilation Versus High-frequency Oscillatory Ventilation for Congenital Diaphragmatic Hernia: a randomized clinical trial (The VICI-trial). Ann Surg. 2016; 263(5):867-74.

30. Van Meurs KV, Congenital Diaphragmatic Hernia Study Group. Is surfactant therapy beneficial in the treatment of the term newborn infant with congenital diaphragmatic hernia? J Pediatr. 2004; 145(3):312-6.

31. Soll RF. Inhaled nitric oxide in the neonate. J Perinatol. 2009; 29(Suppl 2):S63-7.

32. Thiagarajan RR, Barbaro RP, Rycus PT, Mcmullan DM, et al. Extracorporeal Life Support Organization Registry International Report 2016. ASAIO J. 2017; 63(1):60-7.

33. Morini F, Goldman A, Pierro A. Extracorporeal membrane oxygenation in infants with congenital diaphragmatic hernia: a systematic review of the evidence. Eur J Pediatr Surg. 2006; 16(6):385-91.

34. ECLS Registry Report, Extracorporeal Life Support Organization. International Summary. January, 2019. [Accessed on: April 4 $\left.{ }^{\text {th }}, 2019\right]$. Available at: https: / / www. elso.org/ Registry/Statistics/InternationalSummary.aspx. 